\title{
SPC4/PACE4 regulates a TGFß signaling network during axis formation
}

\author{
Daniel B. Constam ${ }^{1,2}$ and Elizabeth J. Robertson ${ }^{1,3}$ \\ ${ }^{1}$ Department of Molecular and Cellular Biology, Harvard University, Cambridge, Massachusetts 02138 USA
}

In vertebrates, specification of anteroposterior $(\mathrm{A} / \mathrm{P})$ and left-right $(\mathrm{L} / \mathrm{R})$ axes depends on TGF $\beta$-related signals, including Nodal, Lefty, and BMPs. Endoproteolytic maturation of these proteins is probably mediated by the proprotein convertase SPC1/Furin. In addition, precursor processing may be regulated by related activities such as SPC4 (also known as PACE4). Here, we show that a proportion of embryos lacking SPC4 develop situs ambiguus combined with left pulmonary isomerism or complex craniofacial malformations including cyclopia, or both. Gene expression analysis during early somite stages indicates that $s p c 4$ is genetically upstream of nodal, pitx2, lefty1, and lefty2 and perhaps maintains the balance between Nodal and BMP signaling in the lateral plate that is critical for $\mathrm{L} / \mathrm{R}$ axis formation. Furthermore, genetic interactions between nodal and spc4, together with our analysis of chimeric embryos, strongly suggest that during A/P axis formation, SPC4 acts primarily in the foregut. These findings establish an important role for SPC4 in patterning the early mouse embryo.

[Key Words: Axis formation; mouse embryo; TGF $\beta$ signals; maturation; regulation]

Received February 23, 2000; revised version accepted March 22, 2000.

In the mouse, Nodal activities in the epiblast and overlying visceral endoderm are required for anteroposterior (A/P) axis formation (Conlon et al. 1994; Varlet et al. 1997), whereas at a later stage asymmetric nodal expression in the node and the left lateral plate mesoderm mediates positional information specifying the left side of the embryo (Collignon et al. 1996; Lowe et al. 1996). Asymmetric, left-sided expression has also been documented for the TGF $\beta$-related molecules Lefty1 and Lefty2 (Meno et al. 1996, 1997). The unique structure and the activity of Lefty proteins indicate they may act as antagonists of TGF $\beta$-like signaling molecules including Nodal or BMPs (Meno et al. 1997; Thisse and Thisse 1999|. Moreover, ectopic expression of Nodal, Leftyl, or Lefty2 in chick right lateral plate mesoderm induces the bicoid-related homeobox gene pitx2 that normally is confined to the left side, suggesting Pitx2 acts downstream of Nodal and/or Lefty in the left-right (L/R) signaling pathway (Logan et al. 1998; Piedra et al. 1998; Ryan et al. 1998; Yoshioka et al. 1998). Mutations perturbing the asymmetric expression of these genes in mice may reverse or randomize the body situs and/or result in visceral organ isomerisms (Collignon et al. 1996; Lowe et al. 1996; Meno et al. 1996; Ryan et al. 1998; Meyers and Martin 1999).

\footnotetext{
${ }^{2}$ Present address: Swiss Institute for Experimental Cancer Research (ISREC), CH-1066 Epalinges, Switzerland.

${ }^{3}$ Corresponding author.

E-MAIL ejrobert@fas.harvard.edu; FAX (617) 496-6770.
}

TGF $\beta$-related activities are controlled by multiple regulatory mechanisms. A critical step involves the maturation of inactive precursor proteins via endoproteolytic cleavage, which is thought to occur within the trans-Golgi network prior to secretion (Sha et al. 1989). Recently, recombinant soluble forms of several subtilisin-like proprotein convertases (SPCs), including SPC1/ Furin, SPC4/PACE4, SPC6B, and SPC7, have been shown to cleave purified BMP4 precursor in vitro (Cui et al. 1998). However, results obtained under these experimental conditions need to be interpreted with caution because they may not necessarily reflect a physiological enzyme-substrate interaction. In Xenopus embryos, the serpin-like polypeptide $\alpha 1$-PDX that has been reported to selectively inhibit SPC1 and SPC6 activities (Jean et al. 1998) efficiently blocks the ventralizing activity of BMP4, suggesting that proteases other than SPC1 and SPC6 may be unable to activate BMP4 in vivo (Cui et al. 1998). Likewise in transfected tissue culture cells, we found that SPC7 and SPC6B activities are post-translationally regulated and fail to enhance BMP4 processing (D.B. Constam, unpubl.; Constam and Robertson 1999). Thus, of the known convertases, SPC1 and possibly SPC6A appeared to be solely responsible for BMP4 cleavage.

Recently, we analyzed a loss-of-function mutation of SPC1 in the mouse: SPC1-deficient embryos fail to undergo turning and develop severe ventral closure and heart morphogenesis defects (Roebroek et al. 1998). A nearly identical phenotype has been reported for embryos lacking Smad5, a transcription factor mediating BMP signal transduction (Chang et al. 1999), consistent 
with the idea that SPC1 is required for efficient maturation of BMP activities. However, BMP4- and BMP2-deficient embryos both develop more severe defects (Winnier et al. 1995; Zhang and Bradley 1996), suggesting that processing of these BMPs does not solely depend on SPC1. During gastrulation, both the epiblast and cardiogenic mesoderm transiently express spc6 mRNA, and SPC6A dramatically enhances BMP4 precursor cleavage in cell transfection assays (D.B. Constam and E.J. Robertson, unpubl.; Constam et al. 1996). Thus, SPC1 and SPC6A probably act in concert to ensure optimal activation of BMP ligands.

In Xenopus, inhibition of SPC activities by $\alpha 1$-PDX expression failed to uncover a physiological role for SPC4. However, recombinant SPC4 has been reported to process activin (Cui et al. 1998), and overexpression of SPC4 in tissue culture cells also promotes Nodal maturation (Constam and Robertson 1999). To assess the physiological function of SPC4 in the embryo, and to test its potential regulatory role in the activation of Activin or Nodal signals, we have now generated a loss-of-function mutation of spc4. In the absence of SPC4, a proportion of embryos develop situs defects and/or display complex craniofacial malformations. Analysis of the expression patterns of nodal and putative Nodal target genes suggests that SPC4 may regulate both Nodal processing and the activation of BMPs that normally confine nodal expression to the left side. To identify the tissues where spc4 expression is primarily required, we also studied the distribution of spc4 mRNA by wholemount in situ hybridization and analyzed chimeric embryos composed of wild-type and SPC4-deficient cells. From these experiments we conclude that SPC4 expression in the foregut is critical for anterior CNS development. In addition, SPC4 activities are probably required in the adjacent splanchnic mesoderm to maintain the balance between mutually antagonistic TGF $\beta$ signaling pathways.

\section{Results}

\section{$L / R$ axis defects in SPC4-deficient embryos}

To determine the role of SPC4 during mouse development, a loss-of-function mutation was generated by deleting coding sequence essential for SPC4 activity (Fig. 1A). $s p c 4^{+/-}$mice appeared normal and were fertile. Irrespective of the genetic background, heterozygous intercrosses yielded homozygous mutant viable offspring at nonmendelian frequencies (Fig. 1B; Table 1). To confirm that we had generated a null allele, total RNA from adult brains was analyzed by RNase protection. No wild-type spc4 mRNA and only small quantities of a 309-nucleotide product corresponding to a nonfunctional, truncated spc4 transcript were detected in homozygous mutants, indicating that the spc4 locus is inactivated (Fig. 1C).

Genotyping of progeny from heterozygous intercrosses suggested that between $24 \%$ and $28 \%$ of the homozygous mutant embryos die prenatally. Analysis of 13 litters from homozygous mutant intercrosses collected be-
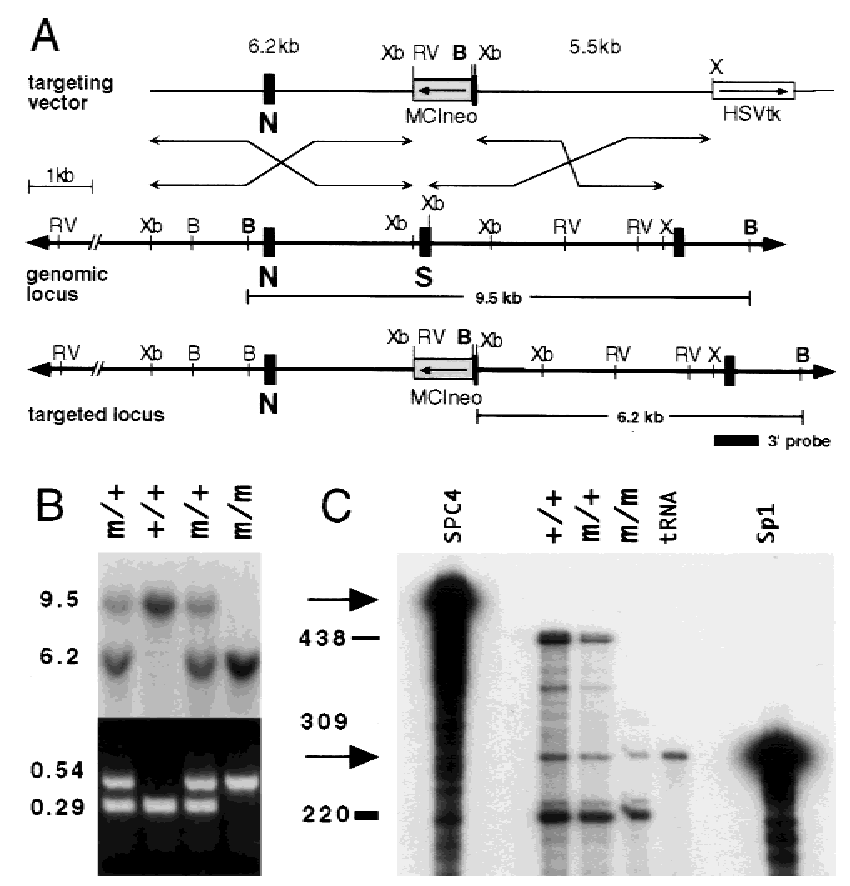

Figure 1. Generation of a loss-of-function allele at the spc4 locus. (A) Schematic representation of the wild-type and mutant alleles and the targeting vector. (B) BamHI; (RV) EcoRV; (Xb) $X b a \mathrm{I} ;(\mathrm{X})$ XhoI. (B) Southern blot and PCR analysis of pups obtained from heterozygous intercrosses. Genomic tail DNA digested with BamHI was hybridized with an external 3'-flanking probe to detect the wild-type $(+)$ or mutant $(\mathrm{m})$ allele, respectively (top). Embryos were genotyped by PCR analysis of yolk sac DNA, amplifying 0.54-kb and 0.29-kb fragments of the mutant or wild-type allele, respectively (bottom). (C) RNase protection analysis. An antisense RNA probe complementary to spc4 sequences comprising the exons designated $\mathrm{N}$ and $\mathrm{S}$ and a control probe specific for mouse Sp-1 (arrows) were hybridized to total RNA obtained from adult brains. Solid bars indicate the position and size of the full-length protected fragments. A partially protected 309-basepair fragment (shaded bar) weakly detectable in homozygous mutants $(\mathrm{m} / \mathrm{m})$ indicates low-level expression of a transcript lacking the coding region for the catalytic serine.

tween embryonic day (E)13.5 and E15.5 confirmed that by E15.5, a corresponding proportion ( $25 \%, n=19$ of 77$)$ of mutant embryos had died (Table 2). Embryonic failure was associated with severe cardiac malformations, including the formation of double outlet right ventricles in combination with ventricular septal defects and in some instances dextrocardia. Common atria were also observed either on the left side or, in association with dex-

Table 1. Offspring of SPC4 heterozygous intercrosses genotyped at weaning

\begin{tabular}{lcrcc}
\hline Background & $+/+^{\mathrm{a}}$ & $+/-^{\mathrm{a}}$ & ${ }^{-/-^{\mathrm{a}}}$ & Total $^{\mathrm{a}}$ \\
\hline 129/C57 hybrid & $99(28)$ & $190(53)$ & $69(19)$ & $358(100)$ \\
129 inbred & $40(27)$ & $84(56)$ & $26(17)$ & $150(100)$ \\
\hline
\end{tabular}

apercent of total given in parentheses. 
Table 2. Combinations of axial defects detected in SPC4 ${ }^{-/-}$embryos

\begin{tabular}{|c|c|c|c|c|c|c|c|c|c|c|c|c|c|c|}
\hline Abnormality & $\mathrm{E} 13.5^{\mathrm{a}}$ & E14.5-15.5 & A & $\mathrm{B}$ & $\mathrm{C}$ & $\mathrm{D}$ & $\mathrm{E}$ & $\mathrm{F}$ & G & $\mathrm{H}$ & $\mathrm{I}$ & $\mathrm{J}$ & $\mathrm{K}$ & $\mathrm{L}$ \\
\hline Dextrocardia & 4 & 1 & & & & & & & $\mathrm{X}$ & $\mathrm{X}$ & $\mathrm{X}$ & $\mathrm{X}$ & & \\
\hline Double outlet right ventricle (DORV) ${ }^{\mathrm{b}}$ & 6 & 2 & $\mathrm{X}$ & & $\mathrm{X}$ & $\mathrm{X}$ & $\mathrm{X}$ & $\mathrm{X}$ & $\mathrm{X}$ & & & $\mathrm{X}$ & & \\
\hline Persistent truncus arteriosus (PTA) & 3 & & & & & & & & & $\mathrm{X}$ & $\mathrm{X}$ & & & \\
\hline Ventricular septal defect (VSD) & 9 & 2 & $\mathrm{X}$ & & $\mathrm{X}$ & $\mathrm{X}$ & $\mathrm{X}$ & $\mathrm{X}$ & $\mathrm{X}$ & $\mathrm{X}$ & $\mathrm{X}$ & $\mathrm{X}$ & & \\
\hline Common left or right atrium & 5 & 1 & & & $\mathrm{X}$ & & & & $\mathrm{X}$ & $\mathrm{X}$ & $\mathrm{X}$ & $\mathrm{X}$ & & \\
\hline Left pulmonary isomerism (LPI) & 9 & 2 & & $\mathrm{X}$ & $\mathrm{X}$ & & $\mathrm{X}$ & $\mathrm{X}$ & $\mathrm{X}$ & $\mathrm{X}$ & $\mathrm{X}$ & $\mathrm{X}$ & & \\
\hline Right-sided stomach, spleen, pancreas & 5 & 1 & & & & & $\mathrm{X}$ & $\mathrm{X}$ & $\mathrm{X}$ & & $\mathrm{X}$ & $\mathrm{X}$ & & \\
\hline Reversed liver situs; hyposplenia & 1 & & & & & & & & & & & & & $\mathrm{X}$ \\
\hline Anterior CNS truncation & 6 & 2 & & & & $\mathrm{X}$ & & $\mathrm{X}$ & $\mathrm{X}$ & $\mathrm{X}$ & $\mathrm{X}$ & $\mathrm{X}$ & $\mathrm{X}$ & \\
\hline Dead & 3 & 1 & & & & & & & & $\mathrm{X}$ & $\mathrm{X}$ & $\mathrm{X}$ & & \\
\hline Resorbed & $4(7)$ & $18(23)$ & & & & & & & & & & & & \\
\hline None $^{c}$ & $43(73)$ & $55(71)$ & & & & & & & & & & & & \\
\hline Total no. of embryos in each group & 59 & 77 & 1 & 2 & 1 & 1 & 2 & 1 & 1 & 2 & 1 & 1 & 2 & 1 \\
\hline
\end{tabular}

${ }^{\text {aPercent }}$ of total given in parentheses. Embryos analyzed between E13.5 and E15.5 were classified into groups A-L based on the combination of abnormalities.

${ }^{\mathrm{b}}$ Double outlet left ventricle in groups G and J.

${ }^{\mathrm{c}}$ The hearts of apparently normal embryos were not sectioned.

trocardia, on the right side (Fig. 2). By E13.5, the deteriorating hearts of three resorbing embryos displayed persistent truncus arteriosus and had formed a single ventricular chamber (Table 2; data not shown), implicating cardiovascular insufficiency as a probable cause of death. Moreover, a proportion of embryos displayed left pulmonary isomerism (Fig. 2D,E). In $\sim 50 \%$ of these animals ( $n=6$ of 11 ; Table 2$)$, the stomach, spleen, and pancreas were abnormally positioned on the right side of the midline (Fig. 2F,G). Specific laterality defects are also detected at E9.5, including reversal of the direction of heart looping ( $n=2$ of 35$)$ or embryo turning $(n=4$ of 35$)$, or both $(n=4$ of 35$)$ in a corresponding proportion $(28 \%)$ of homozygous mutants (Fig. $2 \mathrm{H}, \mathrm{K}$ ). These results establish a function for SPC4 during $\mathrm{L} / \mathrm{R}$ axis formation.

Dual role for SPC4 in the regulation of asymmetric nodal, pitx2, and lefty expression patterns

As might be expected, the laterality defects of spc4 mutants are preceded by specific alterations in the expression patterns of nodal, lefty, and/or the bicoid-related homeobox gene pitx2, a putative target of Nodal signaling. At early somite stages, $71 \%(n=29$ of 41$)$ of the mutant embryos express nodal mRNA in both the left and right lateral plate (Fig. 3; Table 3). Similarly, pitx2 and lefty mRNAs are bilaterally expressed, although in a smaller proportion of mutant embryos $[21 \%(n=5$ of 24$)$ and $15 \%,(n=3$ of 20$)$, respectively]. This disturbance in asymmetric gene expression probably accounts for left pulmonary isomerism, because both lefty 1 and pitx2 impose left-sided pattern on the lung primordia (Meno et al. 1998; Ryan et al. 1998; Gage et al. 1999; Lin et al. 1999; $\mathrm{Lu}$ et al. 1999). On the other hand, a proportion of embryos failed to express either lefty1 ( $n=2$ of 20) or lefty2 $(n=3$ of 20$)$, or both $(n=1$ of 20$)$ in the prospective floor plate or lateral plate mesoderm, respectively (Table 3). We conclude that asymmetric nodal, lefty, and pitx2 gene expression patterns are regulated by SPC4-dependent activities.

The nodal locus contains two FAST transcription factor binding sites that are necessary and sufficient to mediate tissue-specific nodal expression in the lateral plate (Saijoh et al. 2000). Xenopus FAST1 and its mouse homolog, FAST2, cooperate with specific Smad transcription factors to transduce TGF $\beta$, Activin, and Nodal signals, raising the possibility that nodal regulates its own expression via a positive feedback mechanism (Saijoh et al. 2000). If Nodal is required to induce or maintain its own expression in the lateral plate, a failure to appropriately process Nodal precursor might be expected to result in loss of nodal expression. To test this prediction, we reduced the gene dosage of nodal by crossing a lossof-function nodal ${ }^{\text {acz }}$ reporter allele into the spc4 null background (Collignon et al. 1996). Interestingly, only $29 \%$ of the nodal ${ }^{\text {lac } Z /+} ; \mathrm{spc}^{-/-}$embryos examined at the 4- to 8-somite stage express lacZ bilaterally, whereas $47 \%$ show normal left-sided expression, and $24 \%$ fail to activate nodal on either side, even though lac $Z$ expression in the node is unperturbed (Table 3). These findings are consistent with the idea that SPC4 contributes to establish a threshold concentration of Nodal protein necessary to maintain nodal expression in the lateral plate.

\section{SPC4 regulates anterior patterning}

A proportion of spc4 mutants analyzed between E13.5 and E15.5 also displayed complex craniofacial abnormalities, including cyclopia, and anterior truncations marked by the absence of the telencephalon, nasal capsule, and upper and lower jaws (Fig. 4A,B; Table 2). The maxillary and mandibular components of the first branchial arch are often fused (Fig. 4F,K). Midline fusion of the eye anlagen and anterior patterning defects of the CNS are common in embryos lacking a functional prechordal plate (Chiang et al. 1996; Izraeli et al. 1999). This 


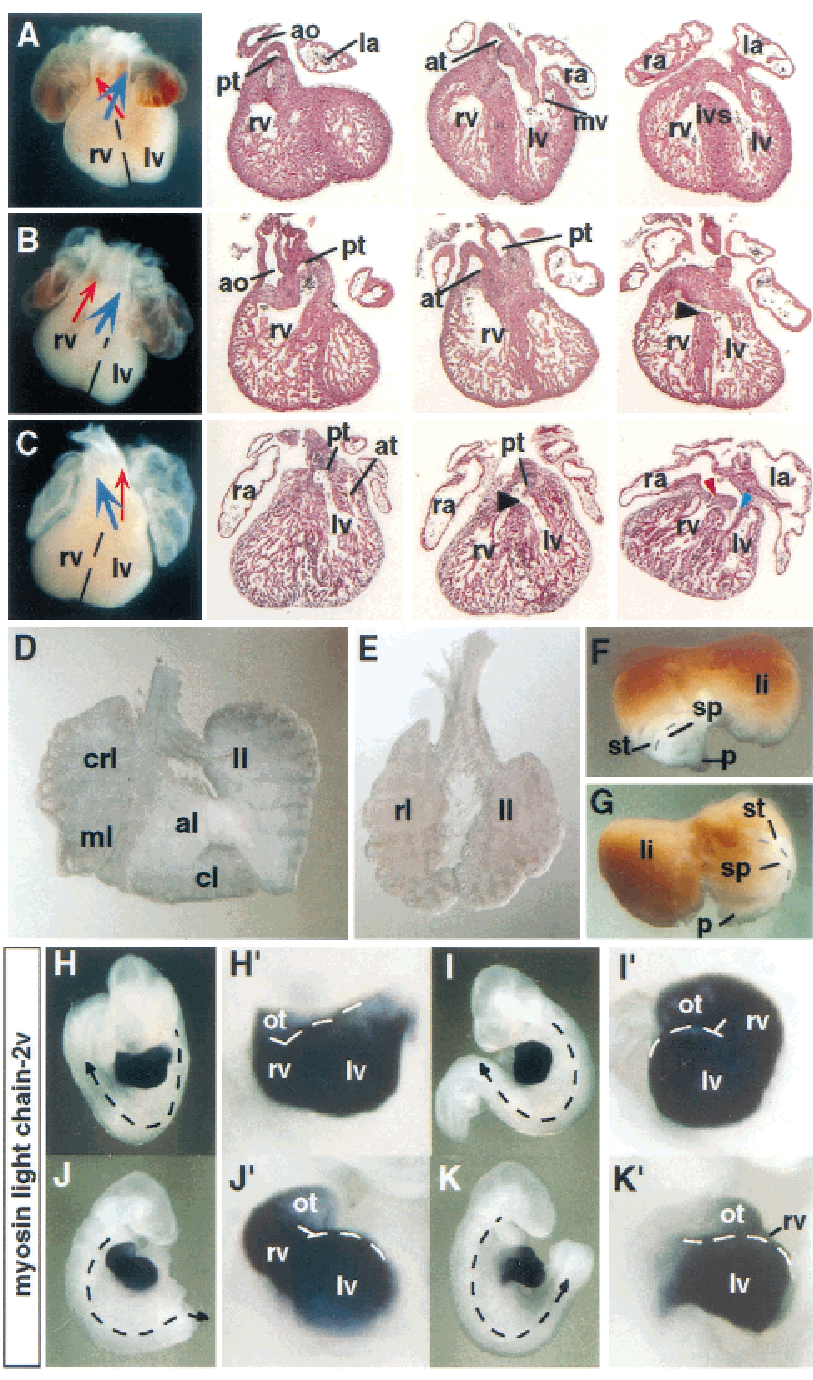

Figure 2. Situs defects of spc4 mutants. $(A-C)$ Whole-mount view and frontal sections of hearts collected from E13.5 embryos. Cardiac abnormalities of spc4 mutants include double outlet right ventricle formation $(B)$ and dextrocardia, associated with ventricular septal defects (black arrowheads), and common right atrium $(C)$. (Red arrowhead) mitral valve; (blue arrowhead) tricuspid valve. $(D, E)$ Left pulmonary isomerism. Whereas normal lungs form four lobes on the right side and only one on the left $(D)$, the lungs of spc4 mutants are often bilaterally symmetric, consisting of one lobe on each side $(E) .(F, G)$ Dorsal view of visceral organs dissected from E13.5 embryos showing wildtype positioning of the stomach, spleen, and pancreatic primordium on the left side $(F)$. The mirror image configuration of an spc4 mutant embryo is shown in $G$. $(H-K)$ Reversal of the direction of heart looping and/or turning in embryos stained for the cardiac marker mlc-2v mRNA. Stippled arrows indicate the direction of turning that is reversed in the embryos shown in $J$ and $K$. Close-up magnifications $\left(H^{\prime}-K^{\prime}\right)$ show abnormal heart looping to the left side $\left(I^{\prime}, K^{\prime}\right)$. (al) Anterior lobe; (ao) aorta; (at) aortic trunk; (cl) caudal lobe; (crl) cranial lobe; (ivs) interventricular septum; (la) left atrium; (li) liver; (ll) left lobe; (lv) left ventricle; (ml) medial lobe; (ot) outflow tract; (pt) pulmonary trunk; (ra) right atrium; (rl) right lobe; (rv) right ventricle; (sp) spleen; (st) stomach; (p) pancreatic primordium.

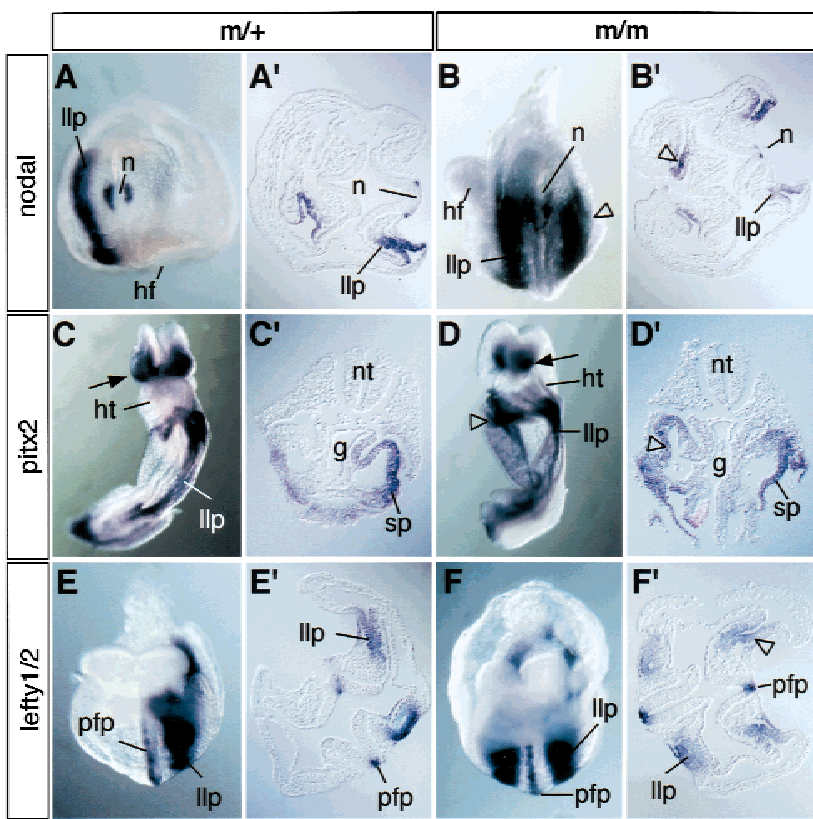

Figure 3. Ectopic expression of nodal, pitx2, and lefty presage laterality defects. $\left(A, A^{\prime}\right)$ Whole-mount in situ hybridization showing wild-type nodal mRNA expression pattern in the node $(\mathrm{n})$ and left lateral plate (llp). $\left(B, B^{\prime}\right)$ Caudal view $(B)$ and transverse section $\left(B^{\prime}\right)$ through the trunk of SPC4-deficient embryos showing ectopic nodal expression on the right side (open arrowheads). $\left(C, C^{\prime}\right)$ Ventral view $(C)$ and transverse section $\left(C^{\prime}\right)$ of control embryo stained to visualize pitx2 mRNA expression in head mesenchyme (arrow) and in the left lateral plate. $\left(D, D^{\prime}\right)$ Ventral-lateral view $(D)$ and section $\left(D^{\prime}\right)$ of mutant embryos showing ectopic pitx2 expression in the splanchnic component of the right lateral plate (open arrowheads). $(E, F)$ Expression of lefty 1 and lefty2 mRNAs in the ventral neural tube and lateral plate mesoderm of control $\left(E, E^{\prime}\right)$ or homozygous mutant embryos $\left(F, F^{\prime}\right)$. (g) Gut; (hf) headfold; (hg) hindgut; (ht) heart; (llp/ rlp) left and right lateral plate; (n) node; (nt) neural tube; (pfp) prospective floorplate; (so) somite; (sp) splanchnic mesoderm.

most anterior aspect of the axial midline forms the roof of the rostral foregut and is responsible for inducing the overlying neurectoderm to acquire anterior character (Dale et al. 1997; Foley et al. 1997). Interestingly, in spc4 mutants showing anterior malformations, the axial midline marked by $h n f 3 \beta$ expression is severely truncated compared with stage-matched control embryos (Fig. $4 C, D)$. This early defect presages the loss of ventral fore-

Table 3. Expression of $L / R$ asymmetry markers in SPC4 mutants

\begin{tabular}{|c|c|c|c|c|c|}
\hline Marker & Left & Bilateral & None & Node & Total \\
\hline nodal & $11(27)$ & $29(71)$ & $1(2)$ & $41(100)$ & 41 \\
\hline nodal ${ }^{1 a c z}$ & $16(47)$ & $10(29)$ & $8(24)$ & $34(100)$ & 34 \\
\hline $\begin{array}{c}\text { lefty } 1 \text { and } \\
\text { lefty } 2\end{array}$ & $\begin{array}{l}111 \mathrm{p} \text { and } \mathrm{pfp}^{\mathrm{a}} \\
21 \mathrm{p} \text {, no pfp } \\
3 \mathrm{pfp} \text {, no } 1 \mathrm{p}\end{array}$ & $3 \mathrm{lp}, \mathrm{pfp}$ & 1 & - & 20 \\
\hline pitx2 & $19(79)$ & $5(21)$ & 0 & - & 24 \\
\hline
\end{tabular}

$\bar{a}(1 \mathrm{p})$ Lateral plate; $(\mathrm{pfp})$ prospective floor plate of the neural tube. 

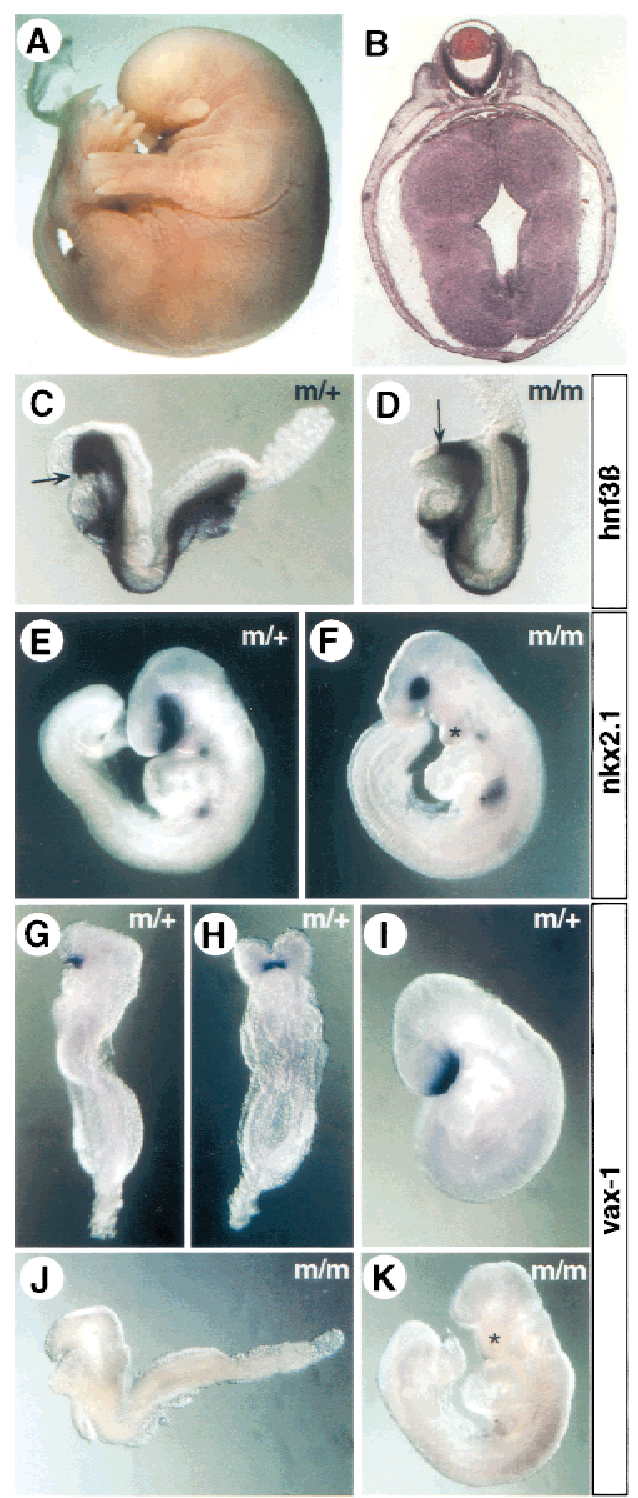

Figure 4. $\mathrm{A} / \mathrm{P}$ axis defects of $s p c 4^{-/-}$embryos. (A) Whole mount view of an E15.5 homozygous mutant showing truncation of the anterior head structures. $(B)$ Coronal section obtained from this embryo showing cyclopia. $(C, D)$ The anterior extension of the axial midline (arrows) marked by the expression of $h n f 3 \beta$ mRNA is truncated in a proportion of homozygous mutant E8.5 embryos $(D)$ compared with heterozygous litter mates $(C) .(E, F)$ Compared with normal E9.5 embryos $(E)$, mutants with craniofacial abnormalities $(F)$ form an abnormally shaped first branchial arch that prematurely fuses at the ventral midline (asterisk; see also in $K$ ), and the number of $n k x 2.1$ expressing cells in the ventral forebrain overlying the prechordal plate mesoderm is significantly reduced $(F) .(G-K)$ Expression of vax1 marking the ventral forebrain between E8.5 $(G, H)$ and E9.5 $(I)$ is abolished in anteriorly truncated, stagematched mutant embryos $(J, K)$.

brain structures expressing $n k x 2.1$ (Fig. 4E,F) and vax1 (Fig. 4G-K). We conclude that SPC4 regulates activities contributed by anterior mesendoderm that are necessary for specifying the ventral forebrain.
SPC4 expression is required in the foregut but not in extraembryonic ectoderm

The establishment of anterior pattern depends on signals from both axial mesendoderm and anterior visceral endoderm (Perea-Gomez et al. 1999; Shawlot et al. 1999). To determine whether spc4 may act in extraembryonic tissues, we examined its expression pattern by wholemount in situ hybridization. spc4 mRNA is abundant in the extraembryonic ectoderm before and during gastrulation, initially in cell populations lining the exocoelomic cavity (E5.5-E7.5) and subsequently throughout the forming chorion (Fig. 5A-C). In contrast, no spc4 mRNA is detectable in the visceral endoderm. Within the embryo, spc 4 transcripts are first detected during early somite stages in the definitive foregut endoderm and adjacent splanchnic mesoderm and at low levels in cephalic mesenchyme (Fig. 5D,E). It seemed likely, therefore, that the $\mathrm{L} / \mathrm{R}$ and anterior CNS defects of spc4 mutants are both due to the loss of SPC4 activity in the embryo itself.

To test this possibility, ES cells heterozygous for the nodal lacz allele (Collignon et al. 1996), but wild type with respect to the spc4 locus, were injected into blastocysts derived from $s p c 4^{-/-}$intercrosses to generate chimeric embryos lacking SPC4 specifically in extraembryonic tissues (Beddington and Robertson 1989). Of 34 chimeric embryos recovered at 4- to 8-somite stages, 31 were efficiently colonized by ES cell derivatives as judged by strong lac $Z$ staining of the node and left lateral plate mesoderm. None of these chimeras displayed anatomical abnormalities or ectopic lacZ expression (data not shown). Thus, spc4 expression in epiblast derivatives is sufficient for normal development.

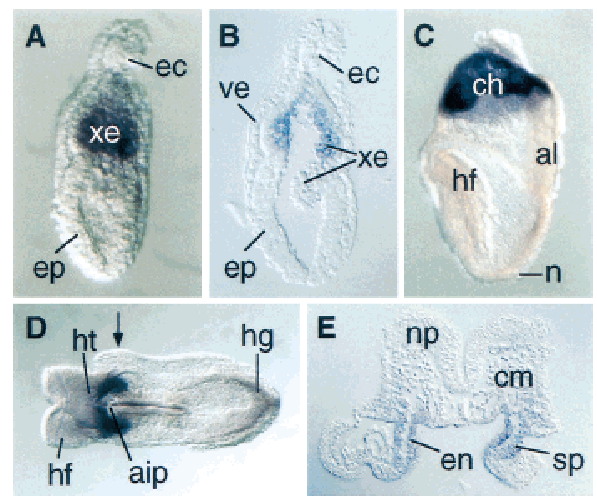

Figure 5. Expression of spc4 mRNA between $6.5 \mathrm{dpc}$ and 8.5 dpc. (A) Whole-mount view and $(B)$ sagittal section of a 6.5-dpc embryo showing expression in the extraembryonic ectoderm lining the exocoelomic cavity. $(C)$ Lateral view of a headfoldstage ( $8.0 \mathrm{dpc}$ ) embryo showing spc4 expression in the chorion. $(D)$ Ventral whole-mount view and $(E)$ transverse section of an 8.5-dpc embryo showing high expression levels in the definitive endoderm of the foregut and adjacent splanchnic mesoderm. Arrow in $D$ indicates where the section in $E$ was obtained. (aip) anterior intestinal portal; (al) allantois; $(\mathrm{ch})$ chorion; $(\mathrm{cm})$ cranial mesenchyme; (ec) ectoplacental cone; (en) definitive endoderm; (ep) epiblast; (hf) headfold; (hg) hindgut; (ht) heart; (np) neural plate; (xe) extraembryonic ectoderm. 
Anterior truncations similar to those seen in spc4 mutants were observed previously in a proportion of embryos trans-heterozygous for nodal and $h n f 3 \beta$ (Collignon et al. 1996) or nodal and smad2 (Nomura and Li 1998) and in nodal heterozygotes lacking ActR-IIA, a putative Nodal receptor (Song et al. 1999). To test for genetic interactions between nodal and spc4, we similarly examined whether loss of one copy of nodal exacerbates the phenotype of spc4 mutants. Interestingly, the notochord of nodal ${ }^{1 a c Z /+}$; spc4 $4^{-/-}$embryos displayed large gaps in the expression of $s h h$ and $h n f 3 \beta$, and the foregut was truncated anteriorly ( $n=4$ of 6 ; Fig. 6; data not shown), demonstrating that nodal and spc4 synergize to promote the formation or maintenance of axial mesendoderm.

\section{Discussion}

Here, we have shown that the proprotein convertase SPC4 has a regulatory function during anterior CNS patterning and $\mathrm{L} / \mathrm{R}$ axis formation. Thus, SPC4-deficient embryos frequently exhibit anterior truncations and/or develop specific laterality defects. Within the embryo itself, spc4 mRNA expression is first detectable throughout the foregut, the rostral roof of which constitutes the endodermal component of the prechordal plate (Seifert et al. 1993). Moreover, severe perturbations of anterior notochord and foregut are observed in nodal ${ }^{1 a c Z /+} ; s p c 4^{-/-}$ embryos. Thus, in spc4 mutants, defective anterior patterning may reflect a specific requirement for SPC4 activity within the endoderm-derived prechordal plate or in maintaining prechordal mesoderm function. Tissue explant recombination assays have shown that during early somite stages the prechordal plate and anterior paraxial mesoderm both contribute diffusible activities sensitizing the neurectoderm to $\mathrm{SHH}$ signals that impart anterior character. This activity can be mimicked by recombinant BMP7 and BMP4, whereas preincubation with anti-BMP7 antibodies blocks activity at least in prechordal plate explants, strongly suggesting BMP signals cooperate with $\mathrm{SHH}$ to pattern the anterior neural plate (Dale et al. 1997). Impaired BMP processing therefore seems most likely to account for the forebrain defects observed in spc4 mutants.

During L/R axis formation, SPC4 also activates a signaling pathway that inhibits nodal expression in the right lateral plate. In the chick, repression of nodal on the right side is mediated by BMP activities that are themselves antagonized on the left side by Caronte, a novel member of the DAN family of secreted BMP antagonists (Rodriguez Esteban et al. 1999; Yokouchi et al. 1999). Also in the mouse, nodal apparently is repressed in the right lateral plate by BMP signals because loss of the BMP effector molecule Smad5 results in bilateral nodal expression (Chang et al. 2000). Repression of nodal and lefty2 in the right lateral plate also requires lefty1 expression (Meno et al. 1998), possibly to prevent diffusion of a Caronte homolog across the midline (Yokouchi et al. 1999). However, because lefty mRNA was abundant in the midline of spc4 mutants showing bilateral expression of lefty2, ectopic induction of lefty2 or nodal unlikely reflects simply a lack of lefty1 expression. Instead, we propose that in spc4 mutants derepression of nodal on the right side is caused by impaired BMP processing in the lateral plate mesoderm or adjacent gut endoderm. Consistent with this, several BMPs are expressed in definitive endoderm, including BMP3, BMP4, BMP6, and BMP7, whereas BMP4, BMP5, and BMP7 are coexpressed in the lateral plate (Dudley and Robertson 1997; Solloway and Robertson 1999).

In marked contrast to the frequent incidence of bilateral nodal expression seen in homozygous spc4 single mutants, spc4 $4^{-/-}$; nodal ${ }^{1 a c Z /+}$ embryos carrying only one functional copy of nodal often fail to induce nodal expression on either side. This is never observed in $s p c 4^{+/+}$
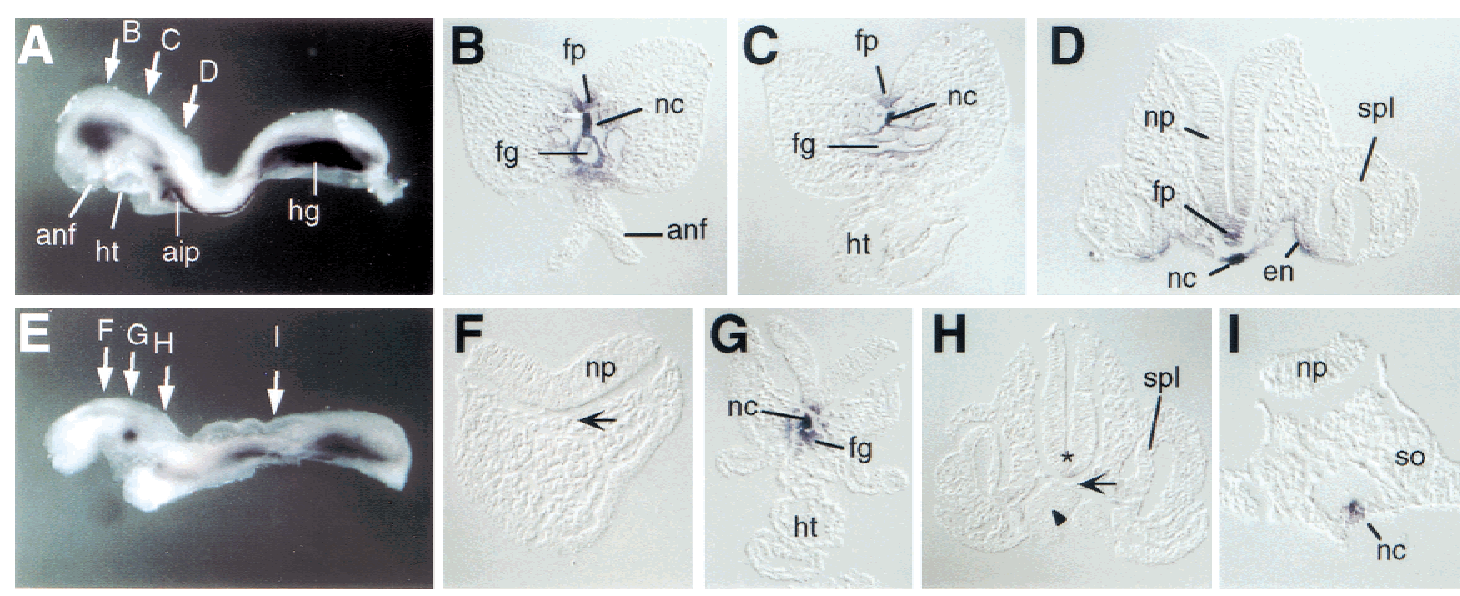

Figure 6. Genetic interaction between spc4 and nodal. $(A, E)$ Whole-mount view and $(B-D, F-I)$ transverse sections of $(A-D)$ wild-type and $(E-I)$ nodal $1^{\text {lac } Z /+}$; spc4 ${ }^{-/-}$embryos stained for shh mRNA expression. $(E-H)$ The foregut and anterior notochord are severely reduced in the mutant $(G)$. Asterisk, arrow, and arrowhead in $F$ and $H$ indicate the absence of notochord, neural tube, and endoderm expression of shh, respectively. (aip) Anterior intestinal portal; (anf) anterior neural fold; (en) endoderm; (fg) foregut; (fp) floor plate; (hg) hindgut; (ht) heart; (nc) notochord; (np) neural plate; (so) somite; (spl) splanchnic mesoderm. 
or $\mathrm{spc}^{+/-}$embryos, suggesting SPC4 promotes nodal feedback signaling. We propose this novel finding reflects a direct role for SPC4 in establishing the threshold concentration of mature Nodal necessary to ensure nodal autoinduction. In normal embryos, Nodal also induces expression of pitx2, as well as Lefty proteins thought to inhibit Nodal feedback signaling (Logan et al. 1998; Meno et al. 1998, 1999; Piedra et al. 1998; Ryan et al. 1998; Yoshioka et al. 1998; Bisgrove et al. 1999). In keeping with this view, a proportion of spc4 mutants also display bilateral pitx2 and lefty expression. However, in a majority of $s p c 4^{-/-}$embryos, bilateral nodal expression is not sufficient to ectopically induce lefty2 or pitx2 in the right lateral plate. Furthermore, a significant proportion of spc4 mutants lack lefty2 expression even in the left lateral plate. This is expected if SPC4 is required for efficient maturation of Nodal activities. On the other hand, because Lefty 2 is a Nodal antagonist, lack of its expression or inhibition of its own maturation should further reduce the threshold concentration of Nodal that is required on the left side to propagate a signal of "leftness," thus facilitating normal development of embryos unable to optimally process Nodal. We propose that in addition to regulating BMP activities, SPC4 also ensures efficient Nodal processing and thus plays an important role in establishing the balance between mutually antagonistic TGF $\beta$ signaling pathways that is critical for $\mathrm{L} / \mathrm{R}$ axis formation (Fig. 7). This simple model is in keeping with results obtained in cell transfection experiments showing efficient cleavage of both BMP4 and Nodal in the presence of SPC4 (Constam and Robertson 1999). However, it does not preclude the likely possiblity that nodal, pitx2, and lefty genes may differentially respond to slight changes in the concentrations of either Nodal or BMP proteins and, perhaps, are differentially modulated by additional signaling pathways.

In Xenopus embryos, BMP4 maturation is abolished by $\alpha 1-P D X$, an SPC inhibitor reported to selectively block SPC1 and SPC6 (Cui et al. 1998; Jean et al. 1998). These data argue that in vivo SPC4 has a unique substrate specificity (Cui et al. 1998). However, another possible explanation for the inability of SPC4 to compensate for SPC1 and/or SPC6 in the presence of $\alpha 1-P D X$ instead may simply be its poor expression levels during early gastrulation stages. Consistent with this idea, the specificities of SPC1 and SPC4 for TGF $\beta$-related substrates in vitro have been shown to overlap (Cui et al. 1998; Constam and Robertson 1999). Another possibility is that $\alpha 1-P D X$ has a higher affinity for Xenopus SPC4 in comparison with its human homolog and thus may also impair SPC4 function in the embryo. $\alpha 1$-PDX recently has also been shown to form SDS-stable complexes with SPC4 and to block its activity (Benjannet et al. 1997; Tsuji et al. 1999). The present experiments clearly demonstrate an important role for SPC4 during early mouse embryogenesis and strongly suggest that BMP activities are regulated by this convertase.

In previous experiments, we have analyzed chimeric embryos composed of wild-type and SPC1/Furin-defi-

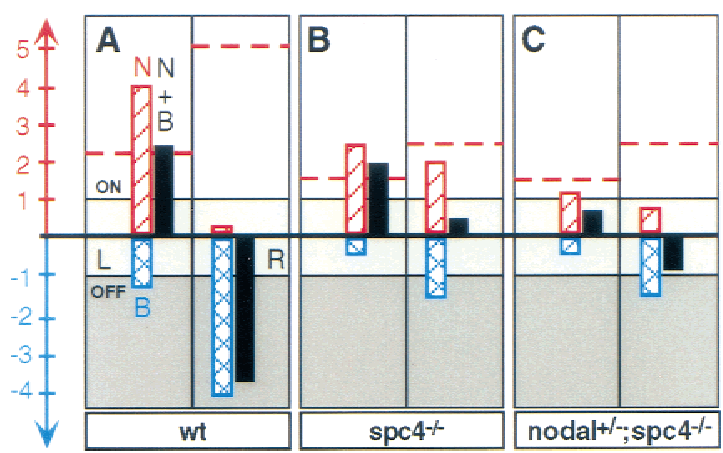

Figure 7. Schematic representation of the proposed mechanism by which SPC4 controls TGF $\beta$-related signals and their target genes during $\mathrm{L} / \mathrm{R}$ axis formation. According to this model, the transcriptional status of Nodal and BMP target genes (solid bars), including nodal, pitx2, and lefties is either OFF (darkly shaded area), ON (lightly shaded area), or ambivalent (intermediately shaded area in between), depending on the net sum of positive and negative regulatory input of Nodal $(\mathrm{N})$ and BMP (B) signals (red hatched bars and blue crosshatched bars, respectively). (A) In wild-type (wt) embryos, BMP signals on the right side (R) effectively repress Nodal target genes but are sequestered on the left side (L) by antagonistic activities (Rodriguez Esteban et al. 1999; Yokouchi et al. 1999; Zhu et al. 1999). Consequently, the threshold concentration of mature Nodal (red broken horizontal line) that is required to reliably induce Nodal target genes is considerably reduced on the left side (arbitrary units for the concentration-dependent regulatory input of mature Nodal and BMP proteins are indicated by the scale bar). (B) According to this model, the threshold concentration of Nodal protein required for activation of its target genes in spc 4 mutants is reduced by an arbitrary factor of twofold because of impaired BMP processing. Because of a similar reduction in the efficiency of Nodal processing, however, mature Nodal still cannot reach the threshold concentrations necessary to reliably overcome the residual inhibitory BMP signals on the right side. Consequently, Nodal targets may fail to become ectopically induced on the right side, even if Nodal concentrations are symmetric with respect to the midline. $(C)$ In spc4 mutants lacking one copy of nodal, the net sum of positive and negative signals is further decreased so that Nodal targets may fail to be reliably induced even on the left side.

cient cells. In contrast to SPC4, SPC1 is required for embryo turning and ventral closure. However, SPC1 is also required to ensure repression of pitx2 and lefty2 in the right lateral plate, implicating SPC1 as a likely regulator of BMP and/or Lefty1 activities (Constam and Robertson 2000). In contrast, it remains unclear whether Nodal signaling depends on SPC1 in vivo. In particular, we failed to observe alterations in nodal mRNA expression patterns in SPC1 mutants (D.B. Constam and E.J. Robertson, unpubl.; Roebroek et al. 1998). Thus, in SPC1 mutants, pitx2 and lefty2 can apparently be derepressed on the right side even if nodal expression is unperturbed, consistent with the assumption of our model that both Nodal and BMPs provide direct positive and negative regulatory input, respectively, into these common target genes (Fig. 7). Based on these considerations, we propose that the fine balance between Nodal and antagonists of nodal expression in the lateral plate is established by 
several SPCs, including SPC1 and SPC4, which partially overlap in their functions. Functional overlap among these proteases may also account for the incomplete penetrance of the spc4 mutant phenotype, and/or explain why spc4 expression in the extraembryonic ectoderm is nonessential. SPC1 and SPC4 mRNAs are coexpressed at high levels both in this extraembryonic tissue and in definitive endoderm and lateral plate mesoderm (Roebroek et al. 1998). Future analysis of SPC1/SPC4 double mutants, therefore, will probably provide further insight into the partially overlapping functions of these proteases during gastrulation.

\section{Materials and methods}

Generation of $\mathrm{spc}^{-/-}$mice

The SPC4 gene targeting vector designed to delete a 280-bp $\mathrm{XbaI}-\mathrm{NcoI}$ fragment, including the coding region for the catalytic serine of SPC4, was derived from a 129SvJ genomic phage library. Restriction map analysis of the SPC4 locus revealed multiple polymorphisms among 129SvJ and 129/SvEv alleles. Therefore, homologous recombination was performed in R1 ES cells derived from an $(129 / \mathrm{SvJ} \times 129 / \mathrm{Sv}) \mathrm{F}_{1}$ hybrid (gift of Dr. J. Rossant, Mount Sinai Hospital, Toronto, Canada). In this cell line, homologous recombination occurred at a frequency of 1 of 30, although exclusively in the SvJ allele (data not shown). Eleven correctly targeted ES cell lines were injected into C57BI/ $6 \mathrm{~J}$ blastocysts, one of which gave rise to germ line chimeras that were backcrossed to C57BI/6J or 129/SvEv females to obtain spc4 heterozygous offspring. For Southern blot analysis, tail DNA samples were digested with BamHI and probed with an external 3 ' genomic fragement detecting $9.5-\mathrm{kb}$ or $6.2-\mathrm{kb}$ fragments corresponding to the wild-type and mutant alleles, respectively. Embryos were genotyped by PCR analysis of yolk sac DNA samples using the intron-specific primer 5'-GGCAGCCGAGGCAGACCAATACAGAG- $3^{\prime}$, in combination with $5^{\prime}$ primers complementary to neomycin cDNA $\left(5^{\prime}\right.$-CCTGCTTGCCGAATATCATGGTGGAAAA- $3^{\prime}$ ), and to exon sequences deleted in the mutant allele $\left(5^{\prime}\right.$-CGCTGCACCGACGGCCA CACT-3'). To confirm that the mutation abolished spc4 expression, total RNA $(20 \mu \mathrm{g})$ from adult brains was subjected to RNase protection analysis using an antisense probe complementary to nucleotides 751-1332 of the murine spc4 cDNA (Hosaka et al. 1994), spanning the deleted region and the entire adjacent upstream exon.

\section{Whole-mount in situ hybridization}

Protocol and probes used for whole-mount mRNA in situ hybridization have been described (Varlet et al. 1997; Constam and Robertson 2000). In addition, an antisense RNA probe hybridizing to both lefty1 and lefty2 transcripts was synthesized using a lefty1 cDNA template (Meno et al. 1996). Nodal transcripts were detected using full-length or exon 2-specific probes. A Vax1-specific probe (Hallonet et al. 1998) was kindly provided by Dr. P. Gruss (Max-Planck Institute, Göttingen, Germany). A 2.1-kb nkx2.1 cDNA probe was provided by Dr. J. Rubenstein (UCSF).

\section{Analysis of chimeric embryos}

Chimeric embryos lacking SPC4 specifically in extraembryonic lineages were generated by injecting $\mathrm{spc}^{-/-}$blastocysts ob- tained from homozygous mutant intercrosses with ES cells carrying one copy of a nodal lacz reporter allele (Collignon et al. 1996). At stage E8.5, the resulting chimeras were stained for lacZ expression as described (Hogan et al. 1994).

\section{Acknowledgments}

We thank Elizabeth Bikoff, Dominic Norris, and Georgy Koentges for critical review of the manuscript and Patricia Lewko and Joseph Rocca for animal care. This work was supported by a grant from the NIH.

The publication costs of this article were defrayed in part by payment of page charges. This article must therefore be hereby marked "advertisement" in accordance with 18 USC section 1734 solely to indicate this fact.

\section{References}

Beddington, R.S.P. and E.J. Robertson. 1989. An assessment of the developmental potential of embryonic stem cells in the midgestation mouse embryo. Development 105: 733-737.

Benjannet, S., D. Savaria, A. Laslop, J.S. Munzer, M. Chretien, M. Marcinkiewicz, and N.G. Seidah. 1997. Alpha1-antitrypsin Portland inhibits processing of precursors mediated by proprotein convertases primarily within the constitutive secretory pathway. J. Biol. Chem. 272: 26210-26218.

Bisgrove, B.W., J.J. Essner, and H.J. Yost. 1999. Regulation of midline development by antagonism of lefty and nodal signaling. Development 126: 3253-3262.

Chang, H., D. Huylebroeck, K. Verschueren, Q. Guo, M.M. Matzuk, and A. Zwijsen. 1999. Smad5 knockout mice die at mid-gestation due to multiple embryonic and extraembryonic defects. Development 126: 1631-1642.

Chang, H., A. Zwijsen, H. Vogel, D. Huylebroeck, and M.M. Matzuk. 2000. Smad5 is essential for left-right asymmetry in mice. Dev. Biol. 219: 71-78.

Chiang, C., Y. Litingtung, E. Lee, K.E. Young, J.L. Corden, H. Westphal, and P.A. Beachy. 1996. Cyclopia and defective axial patterning in mice lacking Sonic hedgehog gene function. Nature 383: 407-413.

Collignon, J., I. Varlet, and E.J. Robertson. 1996. Relationship between asymmetric nodal expression and the direction of embryonic turning. Nature 381: 155-158.

Conlon, F.L., K.M. Lyons, N. Takaesu, K.S. Barth, A. Kispert, B. Herrmann, and E.J. Robertson. 1994. A primary requirement for nodal in the formation and maintenance of the primitive streak in the mouse. Development 120: 1919-1928.

Constam, D.B. and E.J. Robertson. 1999. Regulation of BMP activities by pro domains and proprotein convertases. J. Cell Biol. 144: 139-149.

- 2000. Tissue-specific requirements for the proprotein convertase Furin/SPC1 during embryonic turning and heart looping. Development 127: 245-254.

Constam, D.B., M. Calfon, and E.J. Robertson. 1996. SPC4, SPC6, and the novel protease SPC7 are coexpressed with bone morphogenetic proteins at distinct sites during embryogenesis. J. Cell Biol. 134: 181-191.

Cui, Y., F. Jean, G. Thomas, and J.L. Christian. 1998. BMP4 is proteolytically activated by Furin and/or PC6 during vertebrate embryonic development. EMBO J. 17: 4735-4743.

Dale, J.K., C. Vesque, T.J. Lints, T.K. Sampath, A. Furley, J. Dodd, and M. Placzek. 1997. Cooperation of BMP7 and SHH in the induction of forebrain ventral midline cells by prechordal mesoderm. Cell 90: 257-269. 
Dudley, A.T. and E.J. Robertson. 1997. Overlapping expression domains of bone morphogenetic protein family members potentially account for limited tissue defects in BMP7 deficient embryos. Dev. Dyn. 208: 349-362.

Foley, A.C., K.G. Storey, and C.D. Stern. 1997. The prechordal region lacks neural inducing ability, but can confer anterior character to more posterior neuroepithelium. Development 124: 2983-2996.

Gage, P.J., H. Suh, and S.A. Camper. 1999. Dosage requirement of pitx2 for development of multiple organs. Development 126: 4643-4651.

Hallonet, M., T. Hollemann, R. Wehr, N.A. Jenkins, N.G. Copeland, T. Pieler, and P. Gruss. 1998. Vaxl is a novel homeobox-containing gene expressed in the developing anterior ventral forebrain. Development 125: 2599-2610.

Hogan, B., R. Beddington, F. Costantini, and E. Lacy. 1994. Manipulating the mouse embryo: A laboratory manual. Cold Spring Harbor Laboratory Press, Cold Spring Harbor, NY.

Hosaka, M., K. Murakami, and K. Nakayama. 1994. PACE4 is a ubiquitous endoprotease that has similar but not identical substrate specificity to other KEX2-like processing endoproteases. Biomed. Res. 16: 383-390.

Izraeli, S., L.A. Lowe, V.L. Bertness, D.J. Good, D.W. Dorward, I.R. Kirsch, and M.R. Kuehn. 1999. The SIL gene is required for mouse embryonic axial development and left- right specification. Nature 399: 691-694.

Jean, F., K. Stella, L. Thomas, G. Liu, Y. Xiang, A.J. Reason, and G. Thomas. 1998. alphal-Antitrypsin Portland, a bioengineered serpin highly selective for furin: Application as an antipathogenic agent. Proc. Natl. Acad. Sci. 95: 7293-7298.

Lin, C.R., C. Kioussi, S. O'Connell, P. Briata, D. Szeto, F. Liu, J.C. Izpisua-Belmonte, and M.G. Rosenfeld. 1999. Pitx2 regulates lung asymmetry, cardiac positioning and pituitary and tooth morphogenesis. Nature 401: 279-282.

Logan, M., S.M. Pagan-Westphal, D.M. Smith, L. Paganessi, and C.J. Tabin. 1998. The transcription factor Pitx2 mediates situs-specific morphogenesis in response to left-right asymmetric signals. Cell 94: 307-317.

Lowe, L.A., D.M. Supp, K. Sampath, T. Yokoyama, C.V. Wright, S.S. Potter, P. Overbeek, and M.R. Kuehn. 1996. Conserved left-right asymmetry of nodal expression and alterations in murine situs inversus. Nature 381: 158-161.

Lu, M.F., C. Pressman, R. Dyer, R.L. Johnson, and J.F. Martin. 1999. Function of Rieger syndrome gene in left-right asymmetry and craniofacial development. Nature 401: 276-278.

Meno, C., Y. Saijoh, H. Fujii, M. Ikeda, T. Yokoyama, M. Yokoyama, Y. Toyoda, and H. Hamada. 1996. Left-right asymmetric expression of the TGF beta-family member lefty in mouse embryos. Nature 381: 151-155.

Meno, C., K. Gritsman, S. Ohishi, Y. Ohfuji, E. Heckscher, K. Mochida, A. Shimono, H. Kondoh, W.S. Talbot, E.J. Robertson, A. Schier, and H. Hamada. 1999. Mouse Lefty-2 and zebrafish Antivin are feedback inhibitors of Nodal signaling during vertebrate gastrulation. Mol. Cell 4: 287-298.

Meno, C., A. Shimono, Y. Saijoh, K. Yashiro, K. Mochida, S. Ohishi, S. Noji, H. Kondoh, and H. Hamada. 1998. lefty-1 is required for left-right determination as a regulator of lefty-2 and nodal. Cell 94: 287-297.

Meno, C., Y. Ito, Y. Saijoh, Y. Matsuda, K. Tashiro, S. Kuhara, and H. Hamada. 1997. Two closely-related left-right asymmetrically expressed genes, lefty-1 and lefty-2: Their distinct expression domains, chromosomal linkage and direct neuralizing activity in Xenopus embryos. Genes Cells 2: 513524.

Meyers, E.N. and G.R. Martin. 1999. Differences in left-right axis pathways in mouse and chick: Functions of FGF8 and
SHH. Science 285: 403-406.

Nomura, M. and E. Li. 1998. Smad2 role in mesoderm formation, left-right patterning and craniofacial development. $\mathrm{Na}$ ture 393: 786-790.

Perea-Gomez, A., W. Shawlot, H. Sasaki, R.R. Behringer, and S.L. Ang. 1999. HNF3 $\beta$ and Lim 1 interact in the visceral endoderm to regulate primitive streak formation and anterior-posterior polarity in the mouse embryo. Development 126: 4499-4511.

Piedra, M.E., J.M. Icardo, M. Albajar, J.C. Rodriguez-Rey, and M.A. Ros. 1998. Pitx2 participates in the late phase of the pathway controlling left- right asymmetry. Cell 94: 319-324.

Rodriguez Esteban, C., J. Capdevila, A.N. Economides, J. Pascual, A. Ortiz, and J.C. Izpisua Belmonte. 1999. The novel Cer-like protein Caronte mediates the establishment of embryonic left-right asymmetry. Nature 401: 243-251.

Roebroek, A.J.M., L. Umans, I.G.L. Pauli, E.J. Robertson, F. van Leuven, W.J.M. Van de Ven, and D.B. Constam. 1998. Failure of ventral closure and axial rotation in embryos lacking the proprotein convertase Furin. Development 125: 4863-4876.

Ryan, A.K., B. Blumberg, C. Rodriguez-Esteban, S. YoneiTamura, K. Tamura, T. Tsukui, J. de la Pena, W. Sabbagh, J. Greenwald, S. Choe, D.P. Norris, E.J. Robertson, R.M. Evans, M.G. Rosenfeld, and J.C. Izpisua Belmonte. 1998. Pitx2 determines left-right asymmetry of internal organs in vertebrates. Nature 394: 545-551.

Saijoh, Y., H. Adachi, R. Sakuma, C. Yeol-Yeo, M. Watanabe, H. Hashiguchi, K. Mochida, S. Ohishi, M. Kawabata, K. Miyazono, M. Whitman, and H. Hamada. 2000. Left-right asymmetric expression of lefty- 2 and nodal is induced by a signaling pathway that includes the transcription factor FAST2. Mol. Cell 5: 35-47.

Seifert, R., M. Jacob, and H.J. Jacob. 1993. The avian prechordal head region: A morphological study. J. Anat. 183: 75-89.

Sha, X., A.M. Brunner, A.F. Purchio, and L.E. Gentry. 1989. Transforming growth factor beta 1: Importance of glycosylation and acidic proteases for processing and secretion. Mol. Endocrinol. 3: 1090-1098.

Shawlot, W., M. Wakamiya, K.M. Kwan, A. Kania, T.M. Jessell, and R.R. Behringer. 1999. Lim1 is required in both primitive streak-derived tissues and visceral endoderm for head formation in the mouse. Development 126: 4925-4932.

Solloway, M.J. and E.J. Robertson. 1999. Early embryonic lethality in Bmp5;Bmp7 double mutant mice suggests functional redundancy within the $60 \mathrm{~A}$ subgroup. Development 126: $1753-1768$

Song, J., S.P. Oh, H. Schrewe, M. Nomura, H. Lei, M. Okano, T. Gridley, and E. Li. 1999. The type II activin receptors are essential for egg cylinder growth, gastrulation, and rostral head development in mice. Dev. Biol. 213: 157-169.

Thisse, C. and B. Thisse. 1999. Antivin, a novel and divergent member of the TGFbeta superfamily, negatively regulates mesoderm induction. Development 126: 229-240.

Tsuji, A., E. Hashimoto, T. Ikoma, T. Taniguchi, K. Mori, M. Nagahama, and Y. Matsuda. 1999. Inactivation of proprotein convertase, PACE4, by $\alpha 1$-antitrypsin portland ( $\alpha 1$-PDX), a blocker of proteolytic activation of bone morphogenetic protein during embryogenesis: Evidence that PACE4 is able to form an SDS-stable acyl intermediate with $\alpha 1$-PDX. J. Biochem. 126: 591-603.

Varlet, I., J. Collignon, and E.J. Robertson. 1997. nodal expression in the primitive endoderm is required for specification of the anterior axis during mouse gastrulation. Development 124: $1033-1044$.

Winnier, G., M. Blessing, P.A. Labosky, and B.L.M. Hogan. 1995. Bone morphogenetic protein-4 is required for meso- 
derm formation and patterning in the mouse. Genes \& Dev. 9: 2105-2116.

Yokouchi, Y., K.J. Vogan, R.V. Pearse II, and C.J. Tabin. 1999. Antagonistic signaling by Caronte, a novel Cerberus-related gene, establishes left-right asymmetric gene expression. Cell 98: 573-583.

Yoshioka, H., C. Meno, K. Koshiba, M. Sugihara, H. Itoh, Y. Ishimaru, T. Inoue, H. Ohuchi, E.V. Semina, J.C. Murray, H. Hamada, and S. Noji. 1998. Pitx2, a bicoid-type homeobox gene, is involved in a lefty-signaling pathway in determination of left-right asymmetry. Cell 94: 299-305.

Zhang, H. and A. Bradley. 1996. Mice deficient for BMP2 are nonviable and have defects in amnion/chorion and cardiac development. Development 122: 2977-2986.

Zhu, L., M.J. Marvin, A. Gardiner, A.B. Lassar, M. Mercola, C.D. Stern, and M. Levin. 1999. Cerberus regulates left-right asymmetry of the embryonic head and heart. Curr. Biol. 9: 931-938. 


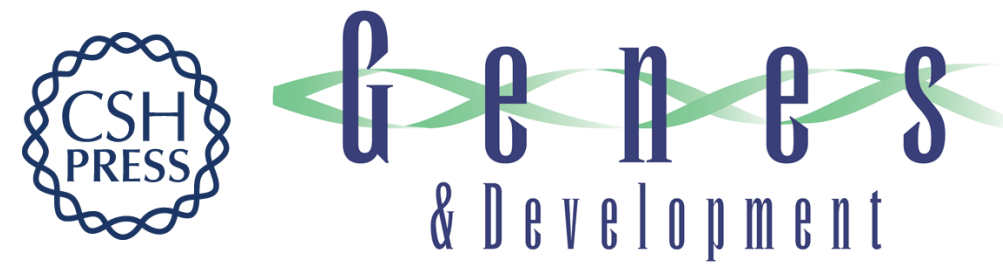

\section{SPC4/PACE4 regulates a TGF $\beta$ signaling network during axis formation}

Daniel B. Constam and Elizabeth J. Robertson

Genes Dev. 2000, 14:

Access the most recent version at doi:10.1101/gad.14.9.1146

References This article cites 47 articles, 22 of which can be accessed free at: http://genesdev.cshlp.org/content/14/9/1146.full.html\#ref-list-1

License

Email Alerting Receive free email alerts when new articles cite this article - sign up in the box at the top Service right corner of the article or click here.

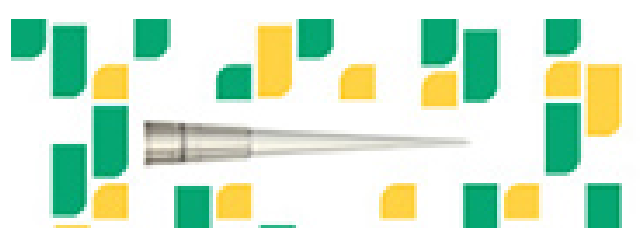

Focused on your science. 